\title{
Technology Scouting to Accelerate Innovation in Supply Chain
}

\author{
Markus Stute, Saskia Sardesai, Matthias Parlings, Pedro Pinho Senna, \\ Rosanna Fornasiero, and Sébastien Balech
}

\begin{abstract}
Digital technologies have gained ground among companies, researchers and policy makers in recent years due to their growing relevance to current and future supply chains. Technologies such as robotics, artificial intelligence, autonomous transport systems, data science, and additive manufacturing are gradually becoming part of people's and companies' daily lives and are changing the manufacturing, process industry and logistics sectors. Although recent attempts have been made to understand the implications of these technologies on supply chain management, the relevance of the different technologies in future scenarios is still unknown. Using a technology scouting approach, the most important enabling technologies for supply chains until 2030 are identified and selected and their implications on future supply chains are evaluated using an assessment methodology with different evaluation criteria.
\end{abstract}

M. Stute $(\bowtie) \cdot$ S. Sardesai $\cdot$ M. Parlings

Fraunhofer Institute for Material Flow and Logistics, Joseph-von-Fraunhofer-Str. 2-4, 44227

Dortmund, Germany

e-mail: Stute.markus@gmail.com

S. Sardesai

e-mail: saskia.wagner-sardesai@iml.fraunhofer.de

M. Parlings

e-mail: matthias.parlings@iml.fraunhofer.de

P. P. Senna

INESC TEC Institute for Systems and Computer Engineering, Technology and Science, Campus da FEUP, Rua Dr. Roberto Frias, 4200, 465 Porto, Portugal

e-mail: pedro.senna@inesctec.pt

R. Fornasiero

Institute of Intelligent Industrial Technologies and Systems for Advanced Manufacturing, National Council of Research (STIIMA-CNR), Via Alfonso Corti, 12, 20133 Milan, Italy e-mail: rosanna.fornasiero@cnr.it

\section{S. Balech}

PNO CONSULTANT, Avenue de la Joyeuse Entrée 1, 1040 Brussels, Belgium

e-mail: sebastien.balech@pnoconsultants.com 
Keywords Enabling technologies $\cdot$ Technology scouting $\cdot$ Supply chain management

\section{Introduction to Enabling Technologies and Technology Scouting}

Enabling technologies can be characterised as widely applicable technologies resulting from advanced scientific and engineering activities that enable the creation of new or the improvement of existing products and services (Commission of the European Communities 2009; Teece 2018). The European Commission describes key enabling technologies as knowledge intensive, multidisciplinary and "associated with high R\&D intensity, rapid innovation cycles, high capital expenditure and highlyskilled employment" (Commission of the European Communities 2009). Enabling and digital technologies are playing an increasingly important role for companies, science and policy makers. Technologies such as robotics, artificial intelligence and additive manufacturing will have strong implications on the structure and management of future supply chains through all industrial sectors (Radanliev et al. 2019; Holmström et al. 2016).

These enabling technologies are not the only factor determining supply chain competitiveness, but they can be one of the key factors for increasing it and applying a specific supply chain strategy (Prajogo and Olhager 2012). Implementing technologies can have an important impact on improving the agility, transparency or reliability of a supply chain (Qrunfleh and Tarafdar 2014). However, supply chain performance also depends on other framework conditions and decisions.

Open innovation is recognised as a critical tool for accelerating growth, and the rapid pace of change in emerging technology markets heightens the importance of scouting and incorporating technologies from the innovation ecosystem (Curley and Salmelin 2013; Rohrbeck et al. 2009). Using a scouting process based on the open innovation paradigm, technology and sector experts were involved in the identification of new technologies necessary to support supply chain evolution until 2030. The technology scouting presented in this chapter aims to identify enabling technologies for supply chains in three industry sectors: discrete manufacturing, the process industry and logistics and distribution. This is achieved through the analysis of existing roadmaps and studies regarding enabling technologies.

Technology scouting is a method for technology foresight analysis (Gudanowska 2014). Technology scouting can be described as the process of collecting knowledge on science and technology at an early stage by using formal and informal information sources including expert knowledge (Gudanowska 2014). It can be used to gather information on specific technological areas or in explorative ways to identify relevant developments (Rohrbeck 2010). Technology scouting includes the process steps of identification, selection and assessment. The main objectives of the technology scouting approach are the early identification of technology trends and the recognition of challenges and opportunities of the technologies (Rohrbeck 2010). Additionally, 
technology scouting constitutes the precedent stage of technology mapping, which will be conducted in a later stage of this research.

This chapter follows a concise structure, with an introduction to enabling technologies and scouting methodology in Sect. 1. The technology scouting methodology is depicted in Sect. 2, which includes the identification and the selection of the enabling technologies as well as the assessment methodology. According to the methodology, Sect. 3 presents a full set of 18 enabling technologies that have been identified, combined with their implementation challenges and industrial impact scoring. Finally, Sect. 4 draws conclusions for the chapter, which also depicts future avenues of research.

\section{Methodological Approach for Technology Scouting}

The technology scouting was conducted as a 3-step process comprising the phases identification, selection and assessment as shown in Fig. 1. This figure presents the general identification, selection and assessment approaches, including five of the analysed technology roadmaps as an example. Figure shows the following four representative studies analysed for the identification of enabling technologies (Identification): VDMA Future Business Trends (VDMA Future Business 2016), the Digital Transformation Scoreboard (European Commission 2017a) and the DHL Logistics Trend Radar (Chung et al. 2018) and Visions of the Future: Transportation and Logistics 2030 (Clausen et al. 2014) as logistics sector studies. The 18 enabling technologies that were selected are listed in the middle of the figure and described in Section 2.3 (Selection). The methodology for the third step (Assessment) is described

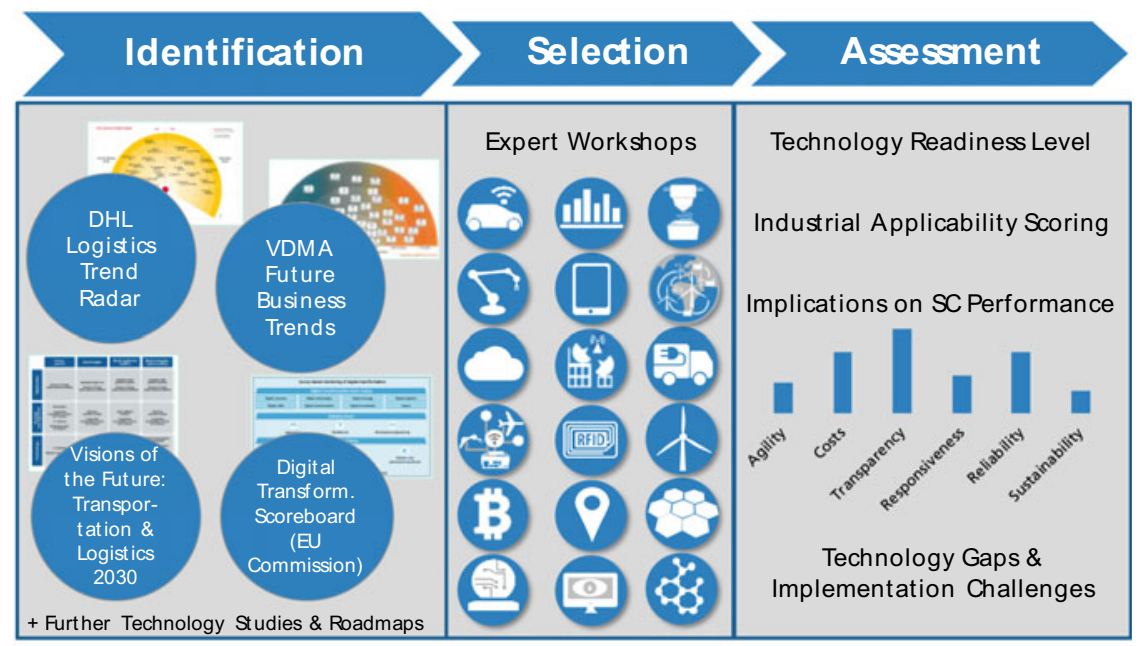

Fig. 1 Methodological approach for technology scouting 
in detail after that. The figure also illustrates that, from a large number of technologies (over 60), 18 enabling technologies were ultimately selected and assessed.

In the following, each step of the methodological approach for the technology scouting is explained in more detail.

\section{Identification}

In order to identify enabling technologies, existing roadmaps and studies at different levels (regional, national, international and sector-specific) were analysed for this work. Nearly 400 technology and sector studies and roadmaps were reviewed by the project partners, including scientific papers, reports and grey literature, with the intent of identifying enabling technologies for supply chains. Moreover, more than 60 current projects were taken into account considering the main EU programs, such as SPIRE - Sustainable Process Industry through Resource and Energy Efficiency (SPIRE 2020) and FOF-Factories of the Future (EFFRA 2020), TRANSPORT (European Commission 2020b) and ICT (European Commission 2020a) as well as other related programs, such as Interreg (Interreg Europe 2020) and Regional Funds. Over 60 technologies were identified in this first step of the technology scouting.

Table 1 shows an extract from the most relevant literature for the three sectors of discrete manufacturing, the process industry and logistics and distribution.

\section{Selection}

In the selection phase, experts from the three sectors of discrete manufacturing, the process industry and logistics and distribution were invited to workshops to select and cluster the enabling technologies. Each project partner first conducted an internal workshop for this purpose. Subsequently, a joint project meeting served to select the most important enabling technologies for future supply chains. As a result, 18 enabling technologies were selected using the technologies identified in the previous identification step. This was achieved by clustering similar technologies and classifying sub-technologies within the 18 enabling technologies.

\section{Assessment Methodology}

In order to evaluate and validate the 18 enabling technologies that had been selected, a technology assessment methodology was performed for each technology with input

Table 1 Most relevant references for the industrial sectors

\begin{tabular}{l|l}
\hline Sector & References \\
\hline Discrete Manufacturing & $\begin{array}{l}\text { Berkers and Jansen (2017), European Commission (2014), } \\
\text { European Commission (2017a), Hallward-Driemeier and Nayyar } \\
\text { (2017), UNIDO (2016) }\end{array}$ \\
\hline Process Industry & $\begin{array}{l}\text { Berkers and Jansen (2017), (DHL Customer Solutions \& } \\
\text { Innovation 2017), (European Commission 2017a), Roland Berger } \\
\text { (2017), (SPIRE) }\end{array}$ \\
\hline Logistics and Distribution & $\begin{array}{l}\text { ALICE (2015), Clausen et al. (2014), Deloitte (2017), Chung et al. } \\
\text { (2018), Kersten et al. (2017) }\end{array}$ \\
\hline
\end{tabular}


from about 30 project experts from the three sectors, and a literature review was also carried out. For the assessment of the enabling technologies, different dimensions were considered to evaluate the identified enabling technologies:

- industrial applicability scoring for the three relevant sectors (discrete manufacturing, the process industry and logistics) and

- implications on supply chain performance based on six criteria.

The assessment dimensions also included a gap analysis of technological gaps and implementation challenges.

Implications on Supply Chain Performance For the evaluation of the implications of each technology on supply chain performance, six criteria based on the SCOR performance attributes (Apics for Business 2019) and the Roland Berger Supply Chain Excellence Study (Roland Berger 2015) served as indicators. Amongst them, the criteria agility, costs, responsiveness and reliability are included in the SCOR performance attributes (Apics for Business 2019). The criteria transparency and sustainability chosen from the Roland Berger Supply Chain Excellence Study (Roland Berger 2015) expand the economic view of the SCOR performance attributes to macro-economic aspects and thus complete the comprehensive view of the implications on supply chain performance.

The following six criteria were defined for the supply chain performance evaluation:

- Agility: Agility is defined as the ability to react to external influences and marketplace changes in order to achieve or maintain competitive advantages. The criterion includes flexibility and adaptability (Apics for Business 2019).

- Costs: The costs criterion refers to the cost of operating the supply chain processes such as labour costs, material costs, management and transportation costs. A typical cost metric is Cost of Goods Sold (Apics for Business 2019).

- Transparency/Traceability: This criterion describes the ability to track a product's flow throughout the production process and supply chain (Doorey 2011; EgelsZandén et al. 2015; Laudal 2010; Roland Berger 2015).

- Responsiveness: Responsiveness describes the speed at which a supply chain provides products to the customer. One metric for responsiveness is the cycle-time (Apics for Business 2019).

- Reliability: Reliability is defined as the ability to perform tasks according to expectations and thus emphasises the predictability of the process output. Metrics for this criterion are, for example: On-time, the right quantity, the right quality (Apics for Business 2019).

- Sustainability: The criterion of sustainability is defined in line with the UN Sustainable Development Goals: esp. 7-Affordable and Clean Energy; 9Industry, Innovation and Infrastructure; and 12-Responsible Consumption and Production (Roland Berger 2015; United Nations 2015).

For each of the six criteria, the scoring for evaluating the implication on SC performance was based on a scale from 1 to 5 , whereby a score of 1 means that 
the technology has strongly negative implications on SC performance regarding the application examples, while a score of 5 implies that the technology has strongly positive implications on SC performance:

1. Strongly negative implications on this criterion are expected

2. Slightly negative implications on this criterion are expected

3. Neutral implications on this criterion are expected

4. Positive implications on this criterion are expected

5. Strongly positive implications on this criterion are expected.

\section{Applicability Scoring}

The applicability scoring refers to the extent of the applications of a specific technology in the three sectors. The applicability scoring in this work uses a scale from 1 to 4 , whereby a score of 1 means that the technology is not widely applicable, while a score of 4 implies that the technology will have broad application throughout that industry sector:

1. No significant application cases are expected for this technology (insignificant applicability)

2. Applicability is limited to special application cases (limited applicability)

3. The technology will have several application cases (moderate applicability)

4. The technology will have broad applicability throughout the industry sector.

The experts rated each supply chain performance criterion on a scale from strongly negative to strongly positive for as well as the industrial applicability of each technology. Based on the ratings, the average value was determined for each sector. The implications on supply chain performance were described by the experts and determined based on literature reviews. Although a relatively high number of technologies were studied and processed numerically to some extent, the nature of this study remains largely qualitative due to the level of interpretation our experts deployed in the assessment tasks.

\section{Gap Analysis}

The gap analysis includes a definition of the technology gaps and the implementation challenges for each selected technology. A comparative analysis of literature, current European projects on these technologies and experts' opinions was carried out to arrive at a shared list of needs. Technology gaps consider technological issues which occur in the current application examples, and which may inhibit the expansion of the technology. The implementation challenges address all technological, organisational, cultural and processual barriers. Furthermore, some initial ideas for overcoming these barriers are provided. 


\section{Enabling Technologies for SC}

In the first step of the methodology, technologies were identified by reviewing the technology and sector studies. These technologies were clustered and selected accordingly on the basis of expert workshops. The result of this selection process is the list of 18 enabling technologies shown in Fig. 2.

This list of the 18 enabling technologies represents one possible classification of the technologies related to supply chains in the three industrial sectors of discrete manufacturing, the process industry and logistics and distribution. This classification is based on numerous expert opinions from these sectors and an extensive literature review as presented in the previous sections.

Between the 18 enabling technologies that were defined there are important interrelationships and dependencies which are briefly addressed in the following subsections and will be further detailed in further stages of this research (especially in the context of mapping the technologies to the future supply chain scenarios).

The Internet of Things (IoT) comprises the autonomous collection and exchange of data from a network of physical devices embedded with sensors, software, network connectivity, and computer capability (PwC 2017). Especially for the manufacturing and logistics sectors, there is broad applicability of IoT. IoT enables easier and faster collection and processing of data to monitor critical parameters. Connected systems will lead to more agility and transparency in the supply chain (Moser 2015; Prasse et al. 2014). Enabling better decision making and process optimisation, the IoT will reduce costs and result in more efficient use of resources (Prasse et al. 2014).

Distributed Ledger/Blockchain The decentralised character of blockchain technology ensures high reliability, enables non-restrictive data transparency throughout the entire supply chain, and allows standardised and transparent business processes (Liang et al. 2017; Jakob et al. 2018). By reducing settlement time as the need for intermediaries is eliminated, and due to the increased and faster sharing of information and the instant access to data, this technology will improve the agility and

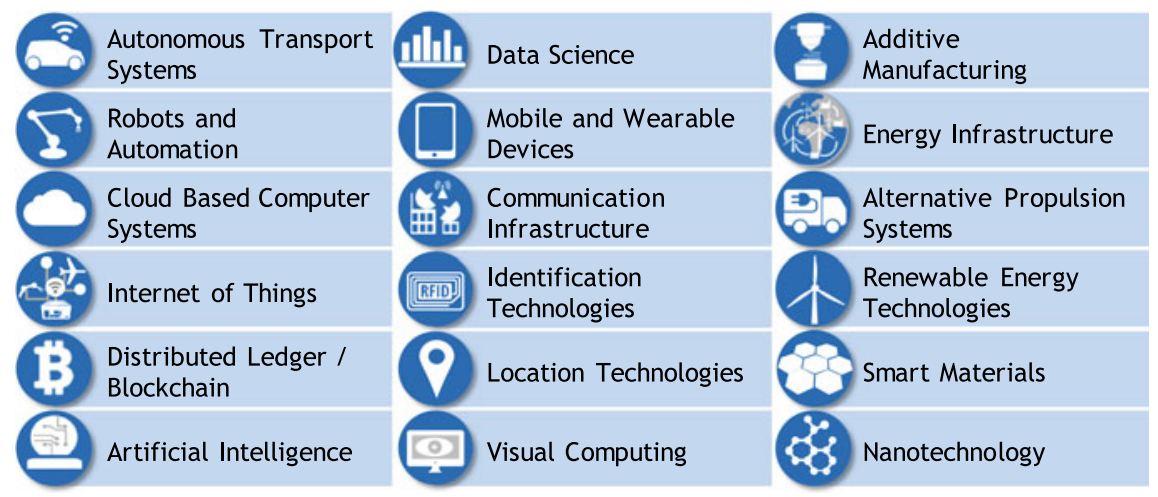

Fig. 2 List of the 18 enabling technologies 
responsiveness of supply chains across all sectors (Dieterich et al. 2017; Jakob et al. 2018). Combined with IoT, this technology is critical for the development of future supply chains, especially in the logistics sector.

Data Science can be defined as the application of quantitative and qualitative methods to solve relevant problems and predict outcomes using algorithms aimed at creating or extracting new information out of vast amounts of data (Cao 2017). The technology will have broad applicability over the three industrial sectors. With large amounts of data available and the ability and willingness to share them efficiently, there will be an improvement of agility and process transparency in supply chains. Costs will be affected positively by more accurate forecasting and the prevention of disruptions (Wang et al. 2016). On the other hand, costs will be affected slightly negatively due to the need to collect and store the data. The negative effects will swiftly decrease as technology advances (Mcafee and Brynjolfsson 2012).

Artificial Intelligence (AI) will greatly affect the performance and development of the future SC industry given its central role in autonomous systems, robots and data science (Chui et al. 2018). Especially for the manufacturing and the logistics sector, the applicability of AI is broad. The implications on SC performance are mostly positive, but transparency may suffer as complex models and algorithms are often seen as a black box and decisions cannot be retraced (Dickson 2017; iapp 2017; Kuang 2018). Nevertheless, AI has the potential to decrease inventory, transportation, labour and disruption management costs due to cycle time and scrap reductions and to improve resource utilisation (McKinsey 2017).

Identification Technologies focus on identifying and tracking goods by using different codes or tags. The sub-technologies such as Radio Frequency Identification (RFID) and barcodes show broad applicability in the logistics sector and positive implications on SC performance, especially with regard to transparency, agility and reliability (Zhu et al. 2012).

Location Technologies are complementary to identification technologies: seamless positioning and tracking capabilities in both outdoor and indoor environments are an important requirement especially for the logistics and distribution sector (Mautz 2012). Real-time location of items during the whole process and real-time information sharing will enable transparency, and have positive implications on the whole supply chain (TexTrace 2016).

Additive Manufacturing (AM) is a technology enabling the creation of lighter, stronger parts and systems through transformative approaches to industrial production. It is considered a genuinely disruptive technology that supports customization while also minimizing waste due to more efficient use of resources (Boon and van Wee 2017). With these characteristics, AM is also seen as a critical technology for the development and improvement of future supply chains with a focus on manufacturing and the logistics industry. 
Autonomous Transport Systems Comprising the sub-technologies of autonomous vehicles (e.g. trucks, trains and ships) and drones, the technology has broad applicability across all industrial sectors. Autonomous transport systems will create opportunities to reduce costs and increase reliability and sustainability by improving resource efficiency due to emissions reductions, fuel efficient driving, improvement of traffic and most likely fewer accidents (Heard et al. 2018; Bugdahn 2017; Chung et al. 2018). Furthermore, the technology will lead to more agility due to easily reconfigurable systems and to increased transparency due to better communication in real-time between and within the systems (Nowak et al. 2016).

Cloud Based Computer Systems are becoming more pervasive in large-scale supply chains as enterprises look to gain agility and speed in resolving complex problems through more effective collaboration (Columbus 2014). Due to easier sharing and processing of information and (real-time) data between different supply chain partners, cloud based computer systems provide opportunities to decrease costs and gain more visibility and transparency (Agorasti Toka et al. 2013). Especially in the logistics sector, there are many application examples and broad applicability of the technology.

Communication Infrastructure aggregates networks and protocols required for the establishment of viable communication between two or more IoT components. The current main sub-technologies are 5G and NarrowBand-IoT (NB-IoT). Since communication infrastructure enables all digitalized technologies it is one of the key enabling technologies for future industrial supply chains (Rao and Prasad 2018; Fettweis 2016). For the three sectors, applicability is moderate to broad and there are positive implications on SC performance for all six criteria.

Robots with their superior sensor technology, control and intelligence, especially in combination with artificial intelligence, have the ability to automate or support human activities and thus have a strong influence on the labour market (Wisskirchen et al. 2017). Main sub-technologies for robots include collaborative robots, which physically interact with humans in shared environments, and autonomous robots, designed for self-reliance and being capable of operating without human assistance or interaction (Djuric et al. 2016). Robots have broad applicability especially in the manufacturing and logistics sector with positive implications on agility and costs (DHL Customer Solutions and Innovation 2016).

Mobile and Wearable Devices are devices which can act autonomously, are noninvasive and perform specific functions, such as monitoring and support over a prolonged time-period. Application examples with broad applicability in all three industrial sectors and positive implications on transparency (Hao and Helo 2017) are smart glasses and smart gloves for barcode scanning.

Visual Computing pursues the goal of extracting information from images and embedding information in images, using image- and model-based information technology by combining computer graphics and computer vision (Fraunhofer IGD 
2018). Sub-technologies like augmented reality (AR) and virtual reality (VR) have broad applicability in the logistics sector, resulting primarily in positive implications regarding transparency (Chung et al. 2018).

Energy Infrastructure technology is designed to provide reliable energy coverage while also optimising energy consumption (Goldthau 2014). Sub-technologies such as smart and neural grids, which mainly focus on the generation, storage and consumption of electric energy, and battery energy storage systems (BESS), which are aimed towards storage capabilities of the grid, are largely still at basic research level and are aiming to have positive implications on the sustainability of future supply chains, especially in the manufacturing sector.

Alternative Propulsion Systems comprise all propulsion engines which use alter-
native means of propulsion when compared to petroleum-based fuels. Therefore,
this technology encompasses advanced biofuels and electromobility enabling overall
sustainability of the future transport sector (IRENA 2016; Storch and Scharrenberg
2019).

Renewable Energy Technologies are aimed at establishing renewable energy resources as the main sources for energy systems. To achieve the EU's objectives for 2030 to reduce greenhouse gas emissions by $40 \%$ compared to 1990 levels (European Commission 2018), technologies such as flywheel energy storage, hydrogen production and storage technology, and advanced biofuels have to be used increasingly. In addition to the positive implications for the sustainability of supply chains, these technologies can also lead to long-term cost savings (International Energy Agency 2014).

Smart Materials are magnetically or electrically controllable materials with outstanding mechanical properties. These materials play an increasingly important role in the development of innovative, versatile and efficient products with a wide range of new functions (Fraunhofer ISC 2018). The positive implications on supply chain performance were assessed as relatively low, but there is broad applicability in the manufacturing sector.

Nanotechnology uses material modifications at the atomic, molecular and supramolecular level to improve functional systems at the molecular level and to design objects with a bottom-up approach aimed at creating sophisticated products (Dwivedi and Dwivedi 2012). With these properties nanotechnology has broad applicability in the manufacturing sector with possible positive implications on costs, reliability and sustainability (National Nanotechnology Initiative; Okoli et al. 2013).

\subsection{Assessment of the Enabling Technologies}

In order to evaluate and visualize the significance of the respective technology, the assessment matrix shown in Fig. 3 is based on the mean scoring for the implications 


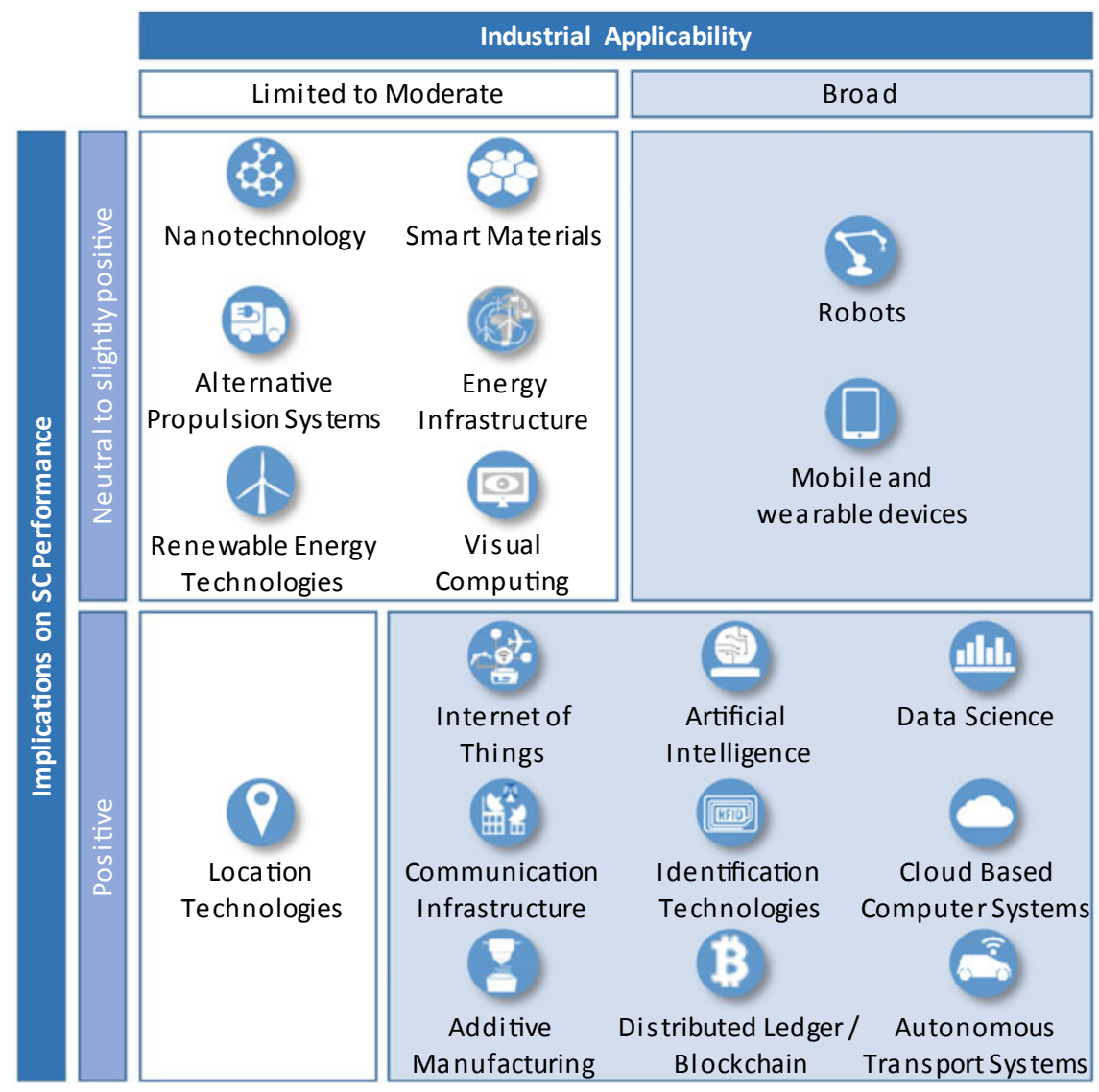

Fig. 3 Assessment of the 18 enabling technologies (implications on SC performance and industrial applicability)

on SC performance for all six criteria and the mean scoring related to applicability over all three sectors for each technology. Figure only shows the quadrants of the assessment matrix where the 18 enabling technologies are positioned, since all of them have at least a limited applicability and neutral implications on SC performance.

The predominantly positive assessments of each technology show that they have the potential to influence future supply chains in a relevant way. Based on this assessment, nine technologies with broad industrial applicability and the most positive implications on the supply chain performance over all three industry sectors were highlighted as key enabling technologies for future research and development: Internet of Things, Artificial Intelligence, Data Science, Communication Infrastructure, Identification Technologies, Cloud Based Computer Systems, Additive Manufacturing, Distributed Ledger/Blockchain and Autonomous Transport Systems. 
It is important to emphasize that the 18 technologies presented here are fundamentally complementary, and that combinations and systems of these technologies therefore enable stronger capability for future supply chains (Sanjiv 2017). This means that the effects of technologies can be more powerful when used as an overarching system. Therefore, further research is necessary for a more comprehensive and complementary analysis of groups of technologies applied to specific supply chain models and dimensions

\subsection{Main Implementation Challenges}

The gap analysis of the technologies revealed some frequent technology gaps and implementation challenges of the respective technologies. These mainly concern standardisation and interoperability and, for a wide range of technologies, data storage, availability, quality and accessibility as well as further processing of these data (e.g. in the form of algorithms).

In fact, system integration is one of the most important implementation challenges identified in nearly all enabling technologies that will enable cross-company, universal data-integration networks with different subsystems, including hardware, software and communications, that need to be integrated (Boston Consulting Group 2018; Gartner IT Glossary 2018; Zhong et al. 2016). System integration should be carried out both horizontally and vertically ensuring different types of collaboration at different levels of supply chains. Vertical integration focuses on integrating processes across the entire organisation via the networking of smart production systems, smart products and smart logistics, whereas horizontal integration encompasses networking along the entire supply chain, from suppliers and business partners to customers, in order to achieve seamless cooperation between companies (Werner 2017).

Due to increased data exchange and connectivity, there is a growing requirement for systems protection with the aid of cyber security (Boston Consulting Group 2018; Radanliev et al. 2019; Bekara 2014). Therefore, appropriate secure and reliable levels of protection regarding the identity and access management of machines, networks, clouds and users have to be ensured with advanced systems such as firewalls, DNS filtering, malware protection and antivirus software (Boston Consulting Group 2018; Gartner 2018).

It is expected that, with respect to SC models, some technologies only influence operations without influencing the structure of the SC or revenue mechanism, while others affect core production and distribution capacity and require a redesign of the supply chain network itself. 


\section{Conclusion}

This chapter identified 18 enabling technologies for the supply chains of the future until 2030 for the three industrial sectors: discrete manufacturing, the process industry and logistics and distribution. The methodology applied was based on a technology scouting approach. A set of enabling technologies was identified by means of a literature review (analysis of existing technology roadmaps and studies), and further clustered into the 18 technologies presented, which were subsequently evaluated using an assessment methodology. The enabling technologies were highlighted for future research and development based on industrial applicability, the implications on supply chain performance and the gap analysis. The main implementation challenges at SC level were identified in system integration and cyber security systems.

The list and assessment of the enabling technologies can be understood as an overview for future technological developments relevant to SC management and may also help companies to focus on the implementation of relevant technologies. Further stages of this research will carry out a mapping methodology to combine the identified enabling technologies with the supply chain strategies which will represent support for the identification and definition of the research and innovation topics depicted in a strategic research agenda.

Acknowledgements The execution and application of this technology scouting methodology have been made possible with the support of a group of experts who participated in the EU project NextNet. We also extend our sincere thanks to our project partners for their fruitful cooperation and for developing the scenarios. Special thanks for their support go to Ana Cristina Barros, Irene Marchiori, Andrea Zangiacomi, Cemre Mutlu, Victoria Muerza, Dimitra Kalaitzi and Aristides Matopolous.

\section{References}

ALICE (2015) Information systems for interconnected logistics: research and innovation roadmap. Available at https://www.etp-logistics.eu/wp-content/uploads/2015/08/W36mayokopie.pdf. Accessed 25 March 2020

Apics for Business (2019) SCOR metrics. Available at https://www.apics.org/apics-for-business/ benchmarking/scormark-process/scor-metrics. Accessed 25 March 2020

Bekara C (2014) Security issues and challenges for the IoT-based smart grid. Procedia Comput Sci 34:532-537

Berkers F, Jansen N (2017) Inspire Project D 2.1: assessment of relevant technologies. Available at http://www.inspire-eu-project.eu/wp-content/uploads/2018/01/INSPIRE-D2.1-Ass essment-of-Relevant-Technologies.pdf. Accessed 25 March 2020

Boon W, van Wee B (2017) Influence of 3D printing on transport: a theory and experts judgment based conceptual model. Transp Rev

Boston Consulting Group (2018) Embracing Industry 4.0. And rediscovering growth. Available at https://www.bcg.com/capabilities/operations/embracing-industry-4.0-rediscovering-gro wth.aspx. Accessed 25 March 2020

Bugdahn P (2017) How autonomous trucks will change the trucking industry. Available at https:// www.geotab.com/blog/autonomous-trucks/. Accessed 25 March 2020 
Cao L (2017) Data science. Commun ACM 60(8):59-68

Chui M, Manyika J, Miremadi M, Henke N, Chung R, Nel P, Malhotra S (2018) Notes from the AI frontier: insights from hundreds of use cases. Available at https://www.mckinsey.com/fea tured-insights/artificial-intelligence/notes-from-the-ai-frontier-applications-and-value-of-deeplearning. Accessed 3 December 2019

Chung G, Gesing B, Chaturvedi K, Bodenbenner P (2018) Logistics trend radar: delivering insight today, creating value tomorrow

Clausen U, Holloh KD, Kadow M (2014) Visions of the future: transportation and logistics 2030, examining the potential for the development of road and rail transportation to 2030

Columbus L (2014) Where cloud computing is improving supply chain performance. Lessons learned from SCM world. Available at https://www.forbes.com/sites/louiscolumbus/2014/02/12/ where-cloud-computing-is-improving-supply-chain-performance-lessons-learned-from-scmworld/\#5948bbb467d3. Accessed 25 March 2020

Commission of the European Communities (2009) Preparing for our future: developing a common strategy for key enabling technologies in the EU: current situation of key enabling technologies in Europe, Brüssel. Available at http://edz.bib.uni-mannheim.de/edz/pdf/sek/2009/sek-2009-1257en.pdf. Accessed 24 March 2020

Curley M, Salmelin B (2013) Open innovation 2.0: a new paradigm. Available at http://ec.europa. eu/information_society/newsroom/cf/dae/document.cfm?doc_id=2182. Accessed 1 July 2019

Deloitte (2017) The 2017 MHI annual industry report next-generation supply chains: digital, ondemand and always-on. Available at https://static1.squarespace.com/static/562164dae4b0099 ac9c04b5c/t/595126ece4fcb533d1d7fe2d/1498490608835/Nextgen+-+MHI+2017+Industry+ Report.pdf. Accessed 23 March 2020

DHL Customer Solutions \& Innovation (2016) Robotics in logistics: a DPDHL perspective on implications and use cases for the logistics industry. Available at http://www.dhl.com/content/dam/dow nloads/g0/about_us/logistics_insights/dhl_trendreport_robotics.pdf. Accessed 25 March 2020

DHL Customer Solutions \& Innovation (2017) The future of life sciences and healthcare logistics: a DHL perspective on key trends and technologies. Available at http://www.dhl.com/con tent/dam/downloads/g0/about_us/logistics_insights/dhl_future_of_lsh_2017.pdf. Accessed 25 March 2020

Dickson B (2017) Artificial intelligence has to deal with its transparency problems. Available at https://thenextweb.com/artificial-intelligence/2017/04/23/artificial-intelligence-has-todeal-with-its-transparency-problems/. Accessed 25 March 2020

Dieterich V, Ivanovic M, Meier T, Utz M, Sandner P (2017) Application of blockchain technology in the manufacturing industry. Available at http://explore-ip.com/2017_Blockchain-Technologyin-Manufacturing.pdf. Accessed 25 March 2020

Djuric AM, Urbanic RJ, Rickli JL (2016) A framework for collaborative robot (CoBot) integration in advanced manufacturing systems. SAE Int J Mater Manuf 9(2):457-464

Doorey DJ (2011) The transparent supply chain: from resistance to implementation at Nike and Levi-strauss. J Bus Ethics 103(4):587-603

Dwivedi A, Dwivedi A (2012) Emerging trends in nano technology for modern industries. Int J Eng Innov Technol (IJEIT) 2(6):4-13

EFFRA (2020) Factories of the future. Available at https://www.effra.eu/factories-future. Accessed 23 March 2020

Egels-Zandén N, Hulthén K, Wulff G (2015) Trade-offs in supply chain transparency: the case of Nudie Jeans Co. J Clean Prod 107:95-104

European Commission (2014) Factories 4.0: the future of European manufacturing. Available at https://ec.europa.eu/digital-single-market/en/blog/factories-40-future-european-manufa cturing. Accessed 25 March 2020

European Commission (2017a) Digital transformation scoreboard 2017. Available at https://ec.eur opa.eu/growth/tools-databases/dem/monitor/sites/default/files/Digital\%20Transformation\%20S coreboard\%202017.pdf. Accessed 25 March 2020 
European Commission (2018) 2030 energy strategy. Available at https://ec.europa.eu/energy/en/ topics/energy-strategy-and-energy-union/2030-energy-strategy. Accessed 5 July 2018

European Commission (2020a) ICT research and innovation. Available at https://ec.europa.eu/pro grammes/horizon2020/en/area/ict-research-innovation. Accessed 23 March 2020

European Commission (2020b) Transport. Available at https://ec.europa.eu/programmes/horizo n2020/en/area/transport. Accessed 23 March 2020

Fettweis GP (2016) 5G and the future of IoT. In: ESSCIRC conference 2016: 42nd European solid-state circuits conference, Lausanne, Switzerland. IEEE, pp 21-24

Fraunhofer IGD (2018) Visual computing. Available at https://www.igd.fraunhofer.de/en/node/885. Accessed 23 March 2020

Fraunhofer ISC (2018) Smart materials. Available at https://www.isc.fraunhofer.de/en/fields-of-act ivity/materials/smart-materials.html. Accessed 5 July 2018

Gartner (2018) Digital business requires cybersecurity. Manage cybersecurity risk effectively across an evolving risk landscape. Available at https://www.gartner.com/en/information-technology/ins ights/cybersecurity. Accessed 25 March 2020

Gartner IT Glossary (2018) System integration. Available at https://www.gartner.com/it-glossary/ system-integration. Accessed 25 March 2020

Goldthau A (2014) Rethinking the governance of energy infrastructure: scale, decentralization and polycentrism. Energ Res Soc Sci 1:134-140

Gudanowska AE (2014) Technology mapping as a tool for technology analysis in foresight studies. In: 2014 IEEE international technology management conference, Chicago, IL. IEEE, pp 1-4

Hallward-Driemeier M, Nayyar G (2017) Trouble in the making? The future of manufacturingled development. Available at https://openknowledge.worldbank.org/bitstream/handle/10986/ 27946/9781464811746.pdf. Accessed 25 March 2020

Hao Y, Helo P (2017) The role of wearable devices in meeting the needs of cloud manufacturing: a case study. Rob Comput Integr Manuf 45:168-179

Heard BR, Taiebat M, Xu M, Miller SA (2018) Sustainability implications of connected and autonomous vehicles for the food supply chain. Resour Conserv Recycl 128:22-24

Holmström J, Holweg M, Khajavi SH, Partanen J (2016) The direct digital manufacturing (r)evolution: definition of a research Agenda. Oper Manag Res 9(1-2):1-10

iapp (2017) Lack of transparency in AI decision. Making a growing concern. Available at https://iapp.org/news/a/limited-transparency-behind-ai-decisions-proves-to-be-concernfor-researchers/. Accessed 29 June 2018

International Energy Agency (IEA) (2014) Technology Roadmap: energy storage. Available at https://www.iea.org/reports/technology-roadmap-energy-storage. Accessed 24 March 2020

Interreg Europe (2020) Interreg Europe. Available at https://www.interregeurope.eu/. Accessed 23 March 2020

IRENA (2016) The renewable route to sustainable transport: a working paper based on remap. Available at https://irena.org/-/media/Files/IRENA/Agency/Publication/2016/IRENA_REmap_ Transport_working_paper_2016.pdf. Accessed 24 March 2020

Jakob S, Schulte AT, Sparer D, Koller R, Henke M (2018) Blockchain und Smart Contracts: Effiziente und sichere Wertschoepfungsnetzwerke

Kersten W, Seiter M, von See B, Hackius N, Maurer T (2017) Trends and strategies in logistics and supply chain management: digital transformation opportunities. Available at https://log istiktrends.bvl.de/en/system/files/t16/2017/Trends\%20and\%20Strategies\%20in\%20Logistics\% 20and\%20Supply\%20Chain\%20Management $\% 20 \%$ E2\%80\%93\%20Digital\%20Transforma tion\%20Opportunities\%20Kersten\%20von\%20See\%20Hackius\%20Maurer.pdf. Accessed 25 March 2020

Kuang C (2018) Can A.I. be taught to explain itself? Available at https://www.nytimes.com/2017/ 11/21/magazine/can-ai-be-taught-to-explain-itself.html?_r=0. Accessed 25 March 2020

Laudal T (2010) An attempt to determine the CSR potential of the international clothing business. J Bus Ethics 96(1):63-77 
Liang X, Shetty S, Tosh D, Kamhoua C, Kwiat K, Njilla L (2017) ProvChain: a blockchain-based data provenance architecture in cloud environment with enhanced privacy and availability. In: 17th IEEE/ACM international symposium on cluster, cloud and grid computing, pp 468-477

Mautz R (2012) Indoor positioning technologies: a survey, 1st edn. Südwestdeutscher Verlag für Hochschulschriften, Saarbrücken

Mcafee A, Brynjolfsson E (2012) Big data: the management revolution. Harvard Bus Rev 90:60-68

McKinsey (2017) Smartening up with artificial intelligence (AI): what's in it for Germany and its industrial sector? Available at https://www.mckinsey.com/ /media/McKinsey/Industries/Sem iconductors/Our\%20Insights/Smartening\%20up\%20with\%20artificial\%20intelligence/Smarte ning-up-with-artificial-intelligence.ashx. Accessed 25 March 2020

Moser T (2015) IoT is ready for the process industry. Available at https://www.isa.org/intech/201 510exec/. Accessed 25 March 2020

Nowak G, Maluck J, Stürmer C, Pasemann J (2016) The era of digitized trucking. Transforming the logistics value chain. Available at https://www.strategyand.pwc.com/reports/era-of-digitized-tru cking. Accessed 25 March 2020

Okoli JU, Briggs TA, Major IE (2013) Application of nanotechnology in the manufacturing sector. A review. Niger J Technol (NIJOTECH) 32(3):379-385

Prajogo D, Olhager J (2012) Supply chain integration and performance: the effects of long-term relationships, information technology and sharing, and logistics integration. Int J Prod Econ 135(1):514-522

Prasse C, Nettstraeter A, Hompel MT (eds) (2014) How IoT will change the design and operation of logistics systems

Qrunfleh S, Tarafdar M (2014) Supply chain information systems strategy: impacts on supply chain performance and firm performance. Int J Prod Econ 147:340-350

Radanliev P, de Roure DC, Page K, Nurse J, Montalvo RM, Santos O, Madox LT, Burnap P (2019) The industrial Internet of Things in the Industry 4.0 supply chains: literature review and future trends. Available at https://arxiv.org/abs/1911.05726v1

Rao SK, Prasad R (2018) Impact of 5G technologies on Industry 4.0. Wirel Pers Commun 100(1):145-159

Rohrbeck R (2010) Harnessing a network of experts for competitive advantage: technology scouting in the ICT industry. R\&D Manag 40(2):169-180

Rohrbeck R, Hölzle K, Gemünden HG (2009) Opening up for competitive advantage-how Deutsche Telekom creates an open innovation ecosystem. R\&D Manag 39(4):420-430

Roland Berger (2015) The supply chain excellence study 2015. Available at https://www.rolandber ger.com/de/Publications/pub_supply_chain_excellence_study_1.html. Accessed 25 March 2020

Roland Berger (2017) Roland Berger trend compendium 2030: megatrend 5 dynamic technology and innovation. Available at https://www.rolandberger.com/en/Publications/pub_trend_compen dium_2030_megatrend_5_dynamic_technology_innovation.html. Accessed 25 March 2020

Sanjiv KR (2017) Innovation through combination of technologies. Available at https://www.wipro. com/blogs/k-r-sanjiv/innovation-through-combination-of-technologies/. Accessed 24 March 2020

SPIRE (2020) Sustainable process industry through resource and energy efficiency. Available at https://www.spire2030.eu/. Accessed 23 March 2020

SPIRE SPIRE roadmap. Available at https://www.spire2030.eu/sites/default/files/pressoffice/spireroadmap.pdf. Accessed 23 March 2020

Teece DJ (2018) Enabling technologies. In: Augier M, Teece DJ (eds) The Palgrave encyclopedia of strategic management, vol 65. Palgrave Macmillan UK, London, pp 499-500

TexTrace (2016) RFID brand label is key to transparency and sustainability.. available at http:// www.textrace.com/assets/docs/White-Paper_TexTrace_Sustainability.pdf. Accessed 4 July 2018

Toka A, Aivazidou E, Arvanitopoulos-Darginis K, Antoniou A (2013) Cloud computing in supply chain management: an overview. In: Graham D, Folinas D, Manikas I (eds) E-logistics and esupply chain management: applications for evolving business. IGI Global (701 E. Chocolate Avenue Hershey Pennsylvania 17033 USA), Hershey, Pa, pp 218-231 
UNIDO (2016) Emerging trends in global advanced manufacturing: challenges, opportunities and policy responses. Available at https://institute.unido.org/wp-content/uploads/2017/06/emerging trends_global_manufacturing.pdf. Accessed 23 March 2020

United Nations (2015) Sustainable development goals. Available at https://www.un.org/sustainab ledevelopment/sustainable-development-goals/. Accessed 25 March 2020

VDMA Future Business (2016) Trendradar für den Maschinen- und Anlagenbau. Available at http:// future.vdma.org/en/trends. Accessed 5 July 2018

von Storch H, Scharrenberg B (2019) Sustainable fuels for logistics: status. Opportunities. Solutions. Available at https://www.dpdhl.com/content/dam/dpdhl/en/media-center/responsibility/ dpdhl-whitepaper-sustainable-fuels-for-logistics.pdf. Accessed 24 March 2020

Wang G, Gunasekaran A, Ngai EWT, Papadopoulos T (2016) Big data analytics in logistics and supply chain management: Certain investigations for research and applications. Int J Prod Econ 176:98-110

Werner H (2017) Supply chain management: Grundlagen, Strategien, Instrumente und Controlling, Lehrbuch, 6., aktualisierte und überarbeitete Auflage, Springer Gabler, Wiesbaden

Wisskirchen G, Biacabe B, Bormann U, Muntz A, Niehaus G, Soler, von Brauchitsch B (2017) Artificial intelligence and robotics and their impact on the workplace. Available at https://www.ibanet.org/Document/Default.aspx?DocumentUid=c06aa1a3-d355-4866beda-9a3a8779ba6e. Accessed 25 March 2020

Zhong RY, Newman ST, Huang GQ, Lan S (2016) Big Data for supply chain management in the service and manufacturing sectors: challenges, opportunities, and future perspectives. Comput Ind Eng 101:572-591

Zhu X, Mukhopadhyay SK, Kurata H (2012) A review of RFID technology and its managerial applications in different industries. J Eng Tech Manage 29(1):152-167

Open Access This chapter is licensed under the terms of the Creative Commons Attribution 4.0 International License (http://creativecommons.org/licenses/by/4.0/), which permits use, sharing, adaptation, distribution and reproduction in any medium or format, as long as you give appropriate credit to the original author(s) and the source, provide a link to the Creative Commons license and indicate if changes were made.

The images or other third party material in this chapter are included in the chapter's Creative Commons license, unless indicated otherwise in a credit line to the material. If material is not included in the chapter's Creative Commons license and your intended use is not permitted by statutory regulation or exceeds the permitted use, you will need to obtain permission directly from the copyright holder.

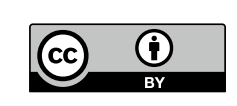

